\title{
Reflexión política
}

\section{Nicaragua desde la danza: revolución y transformación}

\author{
Roberto Picado-Rocha \\ Profesor, bailarín y coreógrafo \\ Escuela Nacional de Danza Adán Castillo, \\ Nicaragua \\ Recibido: 15 de julio de 2019 \\ Aceptado: 20 de diciembre de 2019 \\ DOI: https://doi.org/10.15359/tdna.36-67.6
}

\section{Resumen}

Este ensayo busca compartir con ustedes una visión de la práctica personal de la danza en Nicaragua. Este es un escrito desde mi punto de vista, desde mi realidad y desde lo que me ha tocado hacer por $\mathrm{mi}$ pueblo, Nicaragua, en un antes y un después histórico con el triunfo de la revolución de 1979. Mi visión presenta un panorama d los cambios acaecidos en las artes a partir de dicho proyecto político.

Palabras claves: Danza en Nicaragua, política y arte, desarrollo y arte, arte en América Central, artes en América Latina

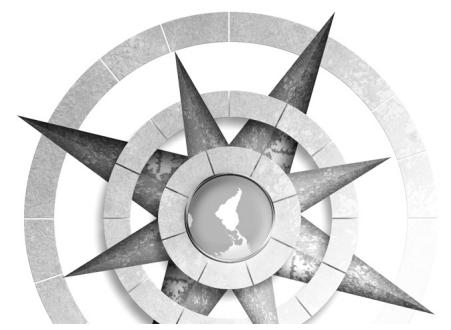

\section{Abstract}

This essay seeks to share my personal vision of the practice of dance in Nicaragua. This is written from my point of view, from my reality and from what I have had to do for my people, Nicaragua, in a historic before and after the triumph of the 1979 revolution. My vision presents a panorama of the changes that have taken place in the arts as a result of that political project.

Keywords: Dance in Nicaragua, politics and arts, development and arts, arts in Central America, arts in Latin America

\section{Resumo}

Este ensaio procura partilhar convosco uma visão da prática pessoal da dança na Nicarágua. Isto está escrito do meu ponto de vista, da minha realidade e do que tive de fazer pelo meu povo, a Nicarágua, num antes e depois histórico, com o triunfo da revolução de 1979. A minha visão apresenta um panorama das mudanças que tiveram lugar nas artes em resultado deste projecto político. 
Palavras chave: Dança na Nicarágua, política e arte, desenvolvimento e arte, arte na América Central, arte na América Latina

En las artes en Nicaragua hay un antes y un después de 1979, año en que triunfa la Revolución Popular Sandinista. En el devenir histórico, el hito es marca, como en todos los contextos de la vida. Antes de aquella época, las artes, en general, y principalmente la danza, eran una exclusividad, porque la ejecutaban y la disfrutaban solo los que tenían el poder económico. Las danzas clásicas y contemporáneas eran exclusivas para las niñas y jóvenes adineradas, porque la danza folklórica era vista como una danza de indios descalzos y jinchos.

Algunos maestros tuvieron el privilegio de recibir clases de técnica clásica o moderna y fue pura suerte del destino y fueron los únicos en hacer en aquel momento, danza académica. Ellos fueron Heriberto Mercado, Alejandro Cuadra, Haydée Palacios y la maestra Irene López maestro de familias humildes, pero con grandes deseos de hacer algo por la danza. Más adelante les contare la herencia y aportes que han dada a la historia de la danza en Nicaragua.

Pero las que lucían bien y brillaban con sus trajes de tutú clásico eran la maestra Ana Amalia Sierra y María Antonieta Siero, que ya para 1979 tenían sus ac- ademias privadas de danza clásica. Es meritorio que ellas después de todo inician y fueron las precursoras de la danza clásica. Hay que reconocer también que fue la maestra Ana Amalia Sierra quién después de 1979, con el apoyo del FSLN crea la Escuela Nacional de Danza Clásica.

En los años sesentas la maestra empírica Chonita Gutiérrez, el canta-autor Camilo Zapata y el papá de la maestra Irene López el señor Francisco López dan los primeros pasos en la conformación de las primeras agrupaciones de proyección artística de los bailes folklóricos nicaragüenses, y luego la maestra Irene López, el profesor Bayardo Ortíz y Antonio Dávila dan continuidad y son los tesoneros de la danza folklórica.

He de mencionar que la danza folklórica se hacía en cada una de las fiestas patronales como una herencia ancestral y parte del pueblo. En el periodo de 1970 a 1978 se crean las agrupaciones folklóricas de la maestra Haydée Palacios. Macehualt del maestro Alejandro Cuadra, Ballet Folklórico Nicaragüense del maestro Ronald Abud, todos ellos apoyados por los colegios y la UNAN de Managua.

Como suelo decir, después de reflexionar sobre la historia, luego de una transformación social, ocurre en el arte también esa transformación, y en

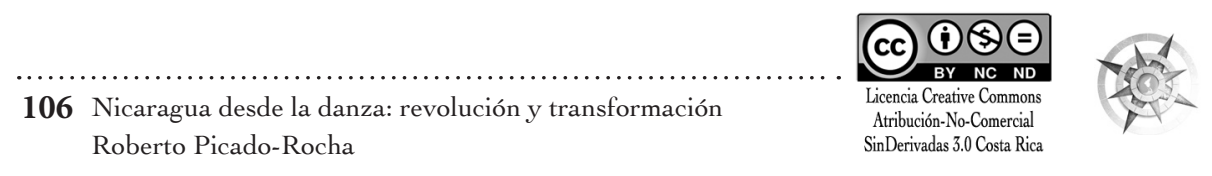


Nicaragua en menos de cincuenta años han ocurrido tres.

La primera en 1979, con el triunfo de la Revolución y es cuando se da la época de ero en Nicaragua del 1979 al 1989, en esos años se fortalece el arte, la cultura y el ámbito social. Y no quiero hacer apología política, pero señalo estos triunfos históricos, desde los que tenemos como resultado la creación de dos Escuelas Nacionales de danza. La primera en el año 1980.

La maestra Irene Lopéz, el profesor Bayardo Ortiz, la maestra Evangelina Villalón, mexicana, y la profesora Patricia López de Colombia fueron fundadores de la Escuela Nacional de Danza en perfiles de danza folklórica y contemporánea. Hoy en día la Escuela Nacional de Danza Adán Castillo.

La segunda, que ya mencioné la Escuela Nacional de Ballet. Además, es fundamental mencionar las Casas de Cultura en cada uno de los municipios del país donde se desarrollan todas las disciplinas del arte. He de agradecer en ese periodo, me refiero a la época de oro, a los maestros de Cuba, México, la URSS y otros países que aportaron su granito de arena para el fortalecimiento de la danza. De Costa Rica contamos con el apoyo de la maestra chilena Elena Gutiérrez, residente en este país, y otros muchos.
Todos estos maestros mencionados de 1979 a 1989 apoyaron el inicio, crecimiento y fortalecimiento de las futuras generaciones de la danza. Como ejemplo, modestia aparte mi persona que acompañado de los compañeros de la primera y segunda graduación de bailarines iniciamos la danza moderna y contemporánea en Nicaragua. Haré mención de algunos compañeros: Gloria Bacon, Guillermo Márquez, Ligia Espinoza, Patricia López, Alenka Díaz, Félida Gaitán, José Wheloock, Elving Vanegas, Rosa María Corea, Verónica Arana Yadira Alemán y otros muchos más que fuimos aportando el granito de arena para ver hoy en día la danza en Nicaragua.

También es importante la conformación de la primera agrupación de danza moderna y contemporánea que dirigió la coreógrafa y bailarina hoy en día Gloria Bacon.

La segunda transformación, se da en el año 1990, cuando se cambian todos los esquemas bajo el Gobierno que dirigía doña Violeta Barrios de Chamorro, primera mujer presidenta, pero que representaba a la derecha y quería borrar todo lo que se había realizado en el periodo del gobierno sandinista. Y todas las artes comienzan a buscar cómo sobrevivir y por supuesto de lanza no queda fuera de ello. La compañía se comienza a desarticular 
y las compañías nacionales creadas en el período precedente desaparecieron. Los bailarines Gloria Bacon, Patricia López, Juan Carlos Barrios y mi persona volvimos a conformar, con otras generaciones. Danza Contemporánea y realizamos el Festival de Danza Contemporánea en Nicaragua.

De 1990 a 2007 se sobrevivió. Pero también se intercambió experiencia con otros países como Finlandia, Suecia, Holanda y otros más. Como bailarín, maestro y coreógrafo, seguí fortaleciendo, formando y creando las nuevas generaciones.

En 1995, específicamente, fundé el grupo infantil de danza moderna y folklórica Studio Experimental 95, con el cual participé en varios festivales del proyecto Margarita Esquivel. Tuve la oportunidad de representar a Nicaragua en varios festivales en Finlandia, luego hice una estadía por dos meses en la Escuela de Danza en Finlandia, gracias al apoyo de los maestros Tarjia Rinne, Alpo Altokoski y otros más. En el año 2000 dejé de bailar y me dediqué ya más a la docencia, esto me llevó a los colegios y las universidades, pero sobre todo y a donde me siento realizado a las comunidades más desprotegidas en municipios y comarcas. Así, puedo decir que desde el año 1987 he compartido talleres de danza en los departamentos de Masaya, León, Chinandega, Estelí, Matagalpa, Boaco, Nueva Segovia, Carazo, Granada y Rivas.
La tercera transformación se dio en el año 2007, cuando vuelve el FSLN al poder. Se ha ido retomando los proyectos artísticos-culturales, ahora con la autonomía de las Alcaldías en cada uno de los departamentos, y aunque el Gobierno central continúa proponiendo, haciendo planes para apoyar y desarrollar las artes, la danza sigue sus esfuerzos de crecer.

A partir del año 2013 estoy en el municipio de Tola Rivas. Donde he formado los dos grupos existentes en el municipio de los Nuevos Tiempos y el grupo de danza Pilas-Coyol. Estos grupos cuentan con integrantes con grandes condiciones y están formando una nueva generación de bailarines. Desde el año 2007 estoy integrado a la Escuela Nacional de Danza Adán Castillo, donde se forman los bailarines profesionales y los instructores de danza folklórica. Esta es mi experiencia, es mi historia, la que puedo contar desde mi país Nicaragua-Nicaragüita. 